\title{
Article
}

\section{Food allergies and perceptions towards food allergen labelling in Mauritius}

Soogali, Bibi Madina amiina nabiilah and Soon, Jan Mei

Available at http://clok.uclan.ac.uk/23074/

Soogali, Bibi Madina amiina nabiilah and Soon, Jan Mei ORCID: 0000-00030488-1434 (2018) Food allergies and perceptions towards food allergen labelling in Mauritius. Food Control . ISSN 0956-7135

It is advisable to refer to the publisher's version if you intend to cite from the work. http://dx.doi.org/10.1016/j.foodcont.2018.06.012

For more information about UCLan's research in this area go to http://www.uclan.ac.uk/researchgroups/ and search for < name of research Group>.

For information about Research generally at UCLan please go to http://www.uclan.ac.uk/research/

All outputs in CLoK are protected by Intellectual Property Rights law, including Copyright law. Copyright, IPR and Moral Rights for the works on this site are retained by the individual authors and/or other copyright owners. Terms and conditions for use of this material are defined in the policies page.

\section{CLoK}

Central Lancashire online Knowledge www.clok.uclan.ac.uk

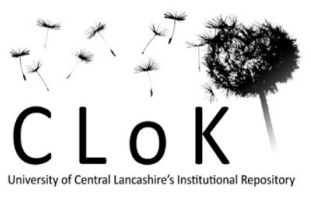


Abstract

There remains a paucity of research in food allergies in Sub-saharan Africa. It is the aim of this study to determine the self-reported prevalence of food allergies and consumers' perceptions towards food allergen labelling in Mauritius. A survey was conducted in four supermarkets in the Municipalities of Vacoas-Phoenix, Quatre-Bornes and Moka during the period of September to November 2017. The questionnaire was designed based on previous studies and administered using a face-to-face interview approach to increase completion rate. Descriptive analysis and one-way ANOVA between subjects design were conducted. Shellfish was reported as the most common causative agent followed by fish, egg and peanut. Respondents were satisfied with the current font size and general information provided in food labels. Respondents agreed that it could be problematic to identify suitable foods for individuals suffering from food allergies or intolerances. Variations of PAL statements and generic terms provided in food labels, and location of allergy warnings were cause for concern. More than $80 \%$ of the respondents felt that allergens in ingredient list should be emphasised (e.g. bold font) and plain English or French language should be used to describe allergenic ingredients. The findings in this study provide practical insights on food allergen labelling issues for policy makers and stakeholders in the food supply chain. Determining the prevalence of food allergies in the country will inform policy makers to consider adding shellfish and other major allergenic ingredients to the list of ingredients requiring mandatory allergen warning label in Mauritius.

Keywords: food allergy; food regulations; precautionary allergen labelling; shellfish

\section{Introduction}

Food allergy is a specific immunological adverse reaction to a trigger food while food intolerance is a form of non-immunologically mediated reaction (Fraser, Sumar, \& Sumar, 2000). Examples of food intolerance include lactose intolerance where the individual lacks the ability to produce sufficient lactase needed to digest lactose. Food allergies can cause life-threatening anaphylactic reactions and reduce the quality of life of individuals with food allergies (Franzese, 2017). Food allergy affects up to 
$10 \%$ of the global population (Sicherer, \& Sampson, 2018) and is increasingly reported in developed nations. For example, the prevalence of food allergy is estimated to be $5-10 \%$ in infants and $5 \%$ in young children in Japan (Ebisawa et al., 2017), 6\% in Europe (Nwaru et al., 2014) and 8\% of children in US (Gupta et al., 2011). Codex stated that the eight common food allergens (cereals containing gluten, egg, milk, soy, peanuts, tree nuts, fish and shellfish) shall be declared (Codex Stan 1-1985). There is still a paucity of research in less developing countries such as in the Africa region (Prescott et al., 2013). Africa is also burdened by infectious and non-communicable diseases and lack of recognition of allergy as a clinical specialty due to limited health care infrastructure (El-Gamal, Hossny, El-Sayed, \& Reda, 2017; Potter et al., 2010). To date there are some reports of surrogate measures of food allergy such as self-reported reactions or sensitisation to food (Kung, Steenhoff, \& Gray, 2014) such as those reported in Mozambique (Lunet, Falcao, Sousa, Bay, \& Barros, 2005) and Tanzania (Justin-Temu, Risha, Abla, \& Massawe, 2008). Gray et al. (2014) and Basera et al. (2015) also assessed the prevalence of food allergy in South Africa using questionnaires, skin prick testing and oral food challenge whilst Obeng et al. (2011) studied the prevalence of food sensitisation and reported food allergy among schoolchildren in Ghana. There is one report of food hypersensitivity in Mauritius which revealed that $20 \%$ of the participants reported symptoms of food allergies (PugoGunsam, Cahoolessur, \& Subratty, 2008).

Mauritius is a small island nation in the Indian Ocean with a population of more than 1.2 million (Naidoo, \& Ramseook-Munhurrun, 2016). It is also a thriving international tourism hub since 1974 where the travel and leisure industry contributed more than $10 \%$ of the total Gross Domestic Product (Ladkin, \& Juwaheer, 2000; Statistics Mauritius, 2017). Protecting both local and international visitors are key and the Mauritian government has reinforced and updated the Food and Drugs Act with Food Act 1998 and Food Regulations (1999) since $1^{\text {st }}$ January 2000 (Ministry of Health and Quality of Life, n.d.). The current food labelling regulations establish the standard labelling requirements of prepacked food. There are currently no regulations requiring the mandatory labelling of food allergens in food products containing such ingredients (Food Regulations, 1999). This is understandable as the true prevalence of food allergy in Mauritius and a number of African countries are not known. However, there has been a report stating high self-reported symptoms of food sensitivity especially 
towards seafood (Pugo-Gunsam et al., 2008). Other food safety associated studies such as food additives (Koyratty, Aumjaud, \& Neeliah, 2014), food hygiene practices (Subratty, Beeharry, \& Chan Sun, 2006) and food safety management in fish industry (Ramnauth, Driver, \& Vial, 2008) had been conducted in Mauritius. There is no cure for immunologically mediated food allergy and the main treatment or preventative step is avoidance of the trigger food. One of the key strategies to avoid food allergens is clear and accurate labelling. Studies on consumers' attitudes towards food allergen labelling were conducted mostly in developed nations (Cornelisse-Vermaat, Voordouw, Yiakoumaki, Theodoridis, \& Frewer, 2007; Voordouw et al., 2007). Food allergen labelling plays a crucial role in preventing development of food allergies among allergic individuals. Mfueni et al. (2018) carried out a study in Malawi and found that the country's food allergen labelling was the least demanding compared to other international regulations. This study aims to determine the self-reported incidence of food allergies and awareness of food allergen labelling in Mauritius.

\section{Methodology}

The questionnaire was constructed and divided into 3 sections: (i) demographics; (ii) self-reported food allergies and (iii) food allergen labelling. Several questions on using food labels in managing food allergies were included in Section III. Respondents were asked 'to what extent they agree or disagree on how serious a problem it is to identify suitable foods for individuals with food allergies or intolerances'. This was followed by a section on 'Improvements of food allergen labelling' and respondents were asked how important the improvements or changes were. The questions were developed based on Choi \& Choi (2016), Cornelisse-Vermaat et al. (2007) and Pugo-Gunsam et al. (2008). A pilot study was conducted among 20 participants who were not included in the actual study to evaluate the language, clarity and suitability of wording. Four supermarkets in Municipalities of Vacoas-Phoenix, Quatre-Bornes and Moka were visited during the period of September to November 2017. The supermarkets were visited on both weekdays and weekends as types of shoppers may differ. Individuals visiting the supermarkets in were approached and the purpose of the study was explained to them. The study targeted both males and females of different ages to represent a snapshot of the demographic characteristics of the participants. Participants were invited to participate in the study and interested participants were asked for their signed consent before 
answering the survey questions. Young respondents ( $<18$ years old) could only participate in the survey if their parents provided the consent. The questionnaire was administered using a face-to-face interview approach as this helps to increase response and completion rate (Koyratty et al., 2014). One hundred and thirteen respondents completed the survey. This is similar to Pugo-Gunsam et al. (2008) and Greiwe, Pazheri, \& Schroer (2015).

Statistical analysis

Statistical analyses were carried out using SPSS 24.0 (IBM Corp., NY, USA). Differences between age, gender and education levels were first analysed using one-way ANOVA between subjects design followed by pairwise comparison with Bonferroni's correction. Results were expressed as mean \pm SD and significance level was set at $p<0.05$.

\section{Results and Discussion}

A total of 113 consumers participated in the study with more females (64.6\%) responding to the survey compared to males. This is similar to other studies and reflect the demographics of mostly female adults conducting the shopping as they take more responsibility for shopping and preparing meals (Helgesen \& Nesset, 2010; Juwaheer, Pudaruth, \& Ramdin, 2013; Liu, \& Niyongira, 2017). Participants mostly belong to the age bracket $25-54$ years $(62.83 \%)$, highly educated $(53.98 \%$ held at least a degree) and tend to report their knowledge on food allergen labelling as somewhat knowledgeable (79.65\%). Curtin, Presser, \& Singer (2000) stated that more educated people are more likely to respond to surveys and this could be largely attributable to the subject matter. All respondents reported symptoms of food allergies (including those experienced by their family members). Shellfish, egg, milk and peanuts were the most commonly reported trigger food (Table 1). Most allergic reactions to seafood are IgE-mediated and can cause rapid onset of symptoms ranging from mild symptoms such as cutaneous reactions to severe anaphylactic reaction (Bahna, 2016). Shellfish was the most commonly reported causative agent in Mauritius (Pugo-Gunsam et al., 2008) and Asia (Boye, 2012; Chiang et al., 2007). Lunet et al. (2005) reported seafood allergy as the most frequent in Mozambique whilst crab was one of the major allergenic food in Zimbabwe (Westritschnig et al., 2003). Based on Pugo-Gunsam et al. (2008) and this study, shellfish is reported 
117 as one of the common allergenic food. Fish is an important component of Mauritian diet (Daby, \&

118 Sigurlinnason, 2003) and the strategic location enable the expansion of the fish industry in Mauritius

119 (Ramnauth, Vial, \& Driver, 2008). Due to the availability and frequency of consumption of seafood,

120 this may have led to a higher increase in prevalence of seafood allergy (Lopata, O'Hehir, \& Lehrer,

121 2014; Sharp, \& Lopata, 2014) as evident in regions such as Japan (Ebisawa et al., 2017), Spain

122 (Pascual et al., 2008) and Philippines (Connett et al., 2012).

Insert Table 1 here

Other food products reported to cause allergies among the respondents of this study were eggplant, food colourings, mushroom, chocolate, taro leaves and red and white beans. There are similar reports of unique ethnic food allergens such as eggplant allergy among Indians residing in US (Dinakar, Kamdar, Yarbrough, \& Gupta, 2015) and India (Babu, Mahesh, \& Venkatesh, 2008) and mushroom allergy (Hegde, Das, \& Venkatesh, 2002). Subjects experiencing adverse reactions to eggplants could be due to pharmacologic action of histamine and other non-protein components (Babu et al., 2008). Kumar et al. (2011) demonstrated that red beans showed cross reactivity with other legumes such as peanuts, soybean and chickpea and may induce allergic reactions in humans. Novel food allergens reported elsewhere in Africa include pineapple in Ghana, okra in Nigeria and mopane worm in Botswana (Kung et al., 2014). Similarly, chocolate can trigger headache and migraine due to consumption of increased level of tyramine, which is naturally present in cocoa products (Finocchi, \& Sivori, 2012). There is also a possibility of presence of milk and or nuts in chocolate that caused the sensitivity (Bedford, Yu, Wang, Garber, \& Jackson, 2017).

Respondents reported having experienced symptoms mostly affecting their cutaneous (e.g. hives, eczema) and gastrointestinal (e.g. vomiting) systems followed by respiratory (e.g. shortness of breath), and circulatory systems (e.g. low blood pressure). Although not determined from this survey, anaphylactic reaction can cause hypotension or severe drop in blood pressure. Fourteen respondents reported either themselves or their family members have had experience of hypotension as one of the reactions to food. Food anaphylaxis can occur rapidly or within a few hours and is often 
accompanied by angioedema in the lips, eye or tongue, followed by symptoms associated with other organ systems (e.g. wheezing / bronchospasm, hypotension and vomiting) (Sarinho, \& Lins, 2017). In this case, epinephrine is the first line of treatment (Kemp et al., 2008; Sarinho \& Lins, 2017). About $16 \%$ of the respondents indicated that they bring some forms of medications (e.g. anti-histamines or epi-pen) to treat a food allergic reaction. Forty percent of the respondents opted to see their general practitioner if they suffer from food allergic reactions. However, on the other end of the spectrum, $37.2 \%$ of the respondents chose not to consult any healthcare professionals if they suffer from food allergic reactions (Table 1). Similar to cases of foodborne illnesses, patrons who experienced food poisoning often do not report the incident (Harrison et al., 2014) or seek medical advice (Soon, Singh, \& Baines, 2011). Cornelisse-Vermaat et al. (2007) and Voordouw et al. (2007) where the food allergic consumers

Insert Figure 1 understand. Singla (2010) also reported difficult terminologies and small font sizes were some of the major problems encountered by consumers. Fifty-nine percent of the respondents in this study felt that the ingredient list could provide more information about food allergens in the label. However, space limitation on the label limits how much information can be included (Verbeke, \& Ward, 2006). There is also the potential of information overload to consider as excessive information may create confusion or even boredom among consumers (Salaun, \& Flores, 2001).

\section{The consumers' responses were further evaluated in terms of their perceptions towards the food} labels. $56.6 \%$ of the respondents agreed that it will be difficult for respondents with food allergies or intolerances if there are different variations of food labels among imported products. Males (3.85 \pm $0.86)$ were more concerned about the different labelling of imported food products $(F=5.97, p=$ 
$\left.1750.016, \mathrm{p \eta}^{2}=0.05\right)$ compared to females $(3.42 \pm 0.89)$. Lack of harmonisation in food labelling

176 practices across imported countries can cause confusion among consumers and may even restrict

177 consumers' diet (Voordouw et al., 2007). Gender also revealed significant difference in the

178 information provided in E-numbers. Females (3.74 \pm 1.07$)$ were more concerned about details of

179 food additives in the E-numbers $\left(\mathrm{F}=6.21, \mathrm{p}=0.014, \mathrm{p \eta}^{2}=0.05\right)$ compared to males $(3.20 \pm 1.16)$.

180 There were strong agreement regarding the location of allergy warnings and usage of generic terms

181 in ingredient lists (e.g. spices, vegetable oil). Ambiguous labels or terms may compromise consumers'

182 ability to determine the safety of the food products (Joshi, Mofidi, \& Sicherer, 2002). Consumers also

183 felt that there is currently lack of manufacturers' or packers' details in the food labelling and that E-

184 numbers should also provide an indication of types of ingredients. Interestingly, there were no significant differences between education levels. This could be explained by the fact that all respondents reported having experienced food allergies or intolerances themselves or by their family members. This represents a motivated group of respondents who may be keen to see changes in the current food labelling practices.

Insert Table 2

More than $80 \%$ felt that allergens in the ingredient list should be emphasised using bold or capitalised font or highlighted with suitable background colour. Different styles of emphasis could be used to emphasise the presence of allergens in the ingredient list or precautionary allergen labelling. Mfueni et al. (2018) revealed that bold font was the most frequently used font when declaring allergens in ingredient list. Other emphasis include contrasting colour, italics or enlarged font. Simple terms should be used to inform customers of the presence of allergens in the ingredients and this could either be in English or French terms. Complex ingredient terminology such as casein and whey for milk may compromise consumers' safety especially if they do not understand the terminologies for milk protein (Joshi et al., 2002). In Joshi et al. (2002)'s study, only 4 of 60 parents correctly identified all the labels that indicated milk. Simons, Weiss, Furlong, \& Sicherer (2005) reported that allergic reactions were attributed to misunderstanding of label terms or usage of generic terms (e.g. flavour or spice). A large proportion of the respondents felt that symbols could be used to indicate the 
presence of allergens ( $87.6 \%$ ) while $73.5 \%$ indicated that allergy warning could be placed adjacent to

205

206

207

208

209

210

211

212

213

214

215

216

217

218

219

220

221

222

223

224

225

226

227

228

229

230

231

232

the ingredient list. Symbols such as asterisks $(*)$ were used in food labels to indicate presence of allergens. For example, an asterisk could be placed on vitamins* to inform consumers that the vitamins *contain soybean oil or sulphur dioxide* to declare that the product *contains preservative as sulphite in some fruits. Alternatively, internationally recognised symbol such as the Grossed Grain Symbol is used across Europe to signify gluten-free products that conform to high and safe standards of production (Association of European Coeliac Societies, 2015). Slightly more than $60 \%$ indicated that contact details should be included in the labelling and similar number of respondents reported that percentage of allergenic ingredients could be shown in the ingredient list. There were significant difference between age groups regarding manufacturer's contact details $\left(F=3.49, p=0.003, \mathrm{p \eta}^{2}=\right.$ 0.17). Consumers under 17 years old $(3.50 \pm 1.23)$ were significantly less concern about the details compared to other age groups (more than 4.00 score). This is understandable as adults may be contacting the manufacturer on behalf of their allergic children and are responsible for finding out further information about usage of allergenic ingredients in the manufacturing environment. Contact details will enable consumers to communicate with manufacturers as indicated by Simons et al. (2005) where $86 \%$ consumers $(n=486)$ in their study contacted the manufacturers for more information. The Internet of Things (IoT) technologies could be utilised in future by integrating QuickResponse (QR) codes and radio frequency identification tag to food products to enable information sharing within the supply chain and consumers. QR codes that are a form of 2D barcodes will be useful in providing detailed information for allergic consumers (Kerbach et al., 2009).

Shellfish is considered a major (self-reported) cause of food allergies in Mauritius. In the current Mauritian Food Regulations (1999), there is no specification requiring food manufacturers to declare the listing of foods causing hypersensitivity. The Codex General Standard for the Labelling of Prepackaged Foods could be used as an international benchmark with reference to the foods and ingredients known to cause hypersensitivity (Codex Stan 1-1985). The eight foods listed in Codexcereals containing gluten, eggs, milk, peanuts \& soybeans (legumes), tree nuts \& nuts, fish, crustacean and sulphite (> $10 \mathrm{mg} / \mathrm{kg}$ ) contribute to $90 \%$ of food allergic reactions (Bush, \& Hefle, 1996). This study is also of value to the food industry and healthcare practitioners as the findings 
represent a snapshot of the food allergy status in Mauritius. Limited countries in Africa had carried out research in this area (Basra et al., 2015; Gray et al., 2014; Kung et al., 2014) and there remains numerous research and development opportunities for Mauritius and other African countries. Determining the prevalence of food allergies in the country will inform policy makers to consider adding shellfish and other major allergenic ingredients to the list of ingredients requiring mandatory allergen warning label in Mauritius. Studies on assessment of food allergen management in food facilities such as those conducted by Dzwolak (2017) in Poland and Thailand (Waisarayutt et al., 2014) and costs for implementation of food safety and allergen management systems (Cusato et al., 2014) will be beneficial. Studies looking into the knowledge and practices of food handlers in food services (Ajala et al., 2010; Dupuis et al., 2017; Soon, in press) can also be carried out.

\section{Conclusion}

The only current treatment for food allergies is to avoid the trigger food. This relies on accurate and clear declaration of allergens in ingredient list and unambiguous precautionary allergen labelling to inform consumers regarding the presence of allergens. Food allergy is a concern in Mauritius and more resources need to be allocated to determine the prevalence of food allergies. Mauritian consumers would like to see improvements in food allergen labelling such as using bold font to emphasise allergens in the ingredient list, plain English or French terminologies, symbol to indicate presence of allergen and the location of allergy warning adjacent to the ingredient list. Consumers would also like manufacturers or packers to include contact details on the food labels as this would allow consumers to enquire or to seek confirmation about the ingredients used and handling of food allergens on their premises. At this time, there remains extensive work in determining the prevalence of food allergies, investigating current food allergen labelling practices in pre-packaged food, and benchmarking and re-aligning the list of food allergens requiring mandatory declaration in food labels. Studies on consumers' attitudes and purchasing habits of food products with allergens will further identify the needs of public.

\section{References}



allergens: Knowledge and practices of food handlers in restaurants. Food Control, 21(10), 1318-1321.

263

Association of European Coeliac Societies (2015). The Crossed Grain Symbol. Available at: http://aoecs.org/licensing-crossed-grain-symbol [Accessed 19 December 2017].

Babu, B. N. H., Mahesh, P. A., \& Venkatesh, Y. P. (2008). A cross-sectional study on the prevalence of food allergy to eggplant (Solanum melongena L.) reveals female predominance. Clinical \& Experimental Allergy, 38(11), 1795-1802.

Bahna, S. (2016). Not every seafood "allergy" is allergy! Annals of Allergy, Asthma and Immunology, $117,458-461$.

Basera, W., Botha, M., Gray, C. L., Lunjani, N., Watkins, A. S. M., Venter, C., Allen, K. J., Hlela, C., \& Zar, H. J. (2015). The South African food sensitisation and food allergy population-based study of IgE-mediated food allergy: validity, safety, and acceptability. Annals of Allergy, Asthma \& Immunology, 115(2), 113-119.

Bedford, B., Yu, Y., Wang, X., Garber, E. A., \& Jackson, L. S. (2017). A limited survey of dark chocolate bars obtained in the United States for undeclared milk and peanut allergens. Journal of Food Protection, 8044), 692-702.

Boye, J. I. (2012). Food allergies in developing and emerging economies: need for comprehensive data on prevalence rates. Clinical and Translational Allergy, 2(25), doi.org/10.1186/2045-7022-2-25

Bush, R. K., \& Hefle, S. L. (1996). Food allergens. Critical Reviews in Food Science and Nutrition, 36, S119-S163.

Chiang, W. C., Kidon, M. I., Liew, W. K., Goh, A., Tang, J. P. L., \& Chay, O. M. (2007). The changing face of food hypersensitivity in an Asian community. Clinical \& Experimental Allergy, 377), 10551061.

Codex Stan 1-1985 (2001). Codex General Standard for the Labelling of Prepackaged Foods. Joint FAO/WHO Food Standards Programme Codex Alimentarius Commission. Available at: http://www.fao.org/tempref/docrep/fao/005/y2770E/y2770E00.pdf [Accessed 19 December 2017].

Connett, G. J.Gerez, I., Cabrera-Morales, E. A., Yuenyongviwat, A., Ngamphaiboon, J., Chatchee, P., Sangsupawanich, P., Soh, S.-E., Yap, C.-C., Shek, L. P.-C., \& Lee, B. W. (2012). A population-based study of fish allergy in the Philippines, Singapore and Thailand. International Archives of Allergy and Immunology, 159, 384-390.

Cornelisse-Vermaat, J. R., Voordouw, J., Yiakoumaki, V., Theodoridis, G., \& Frewer, L. J. (2007). Food-allergic consumers' labelling preferences: a cross-cultural comparison. European Journal of Public Health, 18(2), 115-120.

Curtin, R., Presser, S., \& Singer, E. (2000). The effects of response rate changes on the index of consumer sentiment. Public Opinion Quarterly, 64(4), 413-428.

Cusato, S., Gameiro, A. H., Sant'Ana, A. S., Corassin, C. H., Cruz, A. G., \& de Oliveira, C. A. F. (2014). Assessing the costs involved in the implementation of GMP and HACCP in a small dairy factory.

Quality Assurance and Safety of Crops \& Foods, 6(2), 135-139.

Daby, P., \& Sigurlinnason, S. A. (2003). A critical view of the fish processing sector in Mauritius with particular reference to seafood safety and quality assurance. Fisheries Training Programme. Available at: http://innri.unuftp.is/proj03/Daby03PRF.pdf [Accessed 18 December 2017]. 
Dinakar, C., Kamdar, O., Yarbrough, M., \& Gupta, R. (2015). Asian Indian food allergy survey: Unique ethnic food allergens. American College of Allergy, Asthma \& Immunology 2015 Annual Scientific Meeting. Available at: https://www.mdlinx.com/allergy-immunology/conferenceabstract.cfm/55242/?conf id=207968\&searchstring=\&coverage day $=0$ \&nonus=0\&page $=1$ [Accessed 12 February 2018].

Dupuis, R., Meisei, Z., Grande, D., Strupp, E., Kounaves, S., Graves, A., Frasso, R., \&Cannuscio, C. C. (2016). Food allergy management among restaurant workers in a large U.S. city. Food Control 63, 147-157.

Dzwolak, W. (2017). Assessment of food allergen management in small food facilities. Food Control 73, 323-331.

Ebisawa, M., Ito, K., Fujisawa, T., Committee for Japanese Pediatric Guideline for Food Allergy, The Japanese Society of Pediatric Allergy and Clinical Immunology, \& The Japanese Society of Allergology. (2017). Japanese guidelines for food allergy 2017. Allergology International, 66(2), 248-264.

El-Gamal, Y. M., Hossny, E. M., El-Sayed, Z. A., \& Reda, S. M. (2017). Allergy and immunology in Africa: Challenges and unmet needs. Journal of Allergy and Clinical Immunology, 4(5), 1240-1243.

Finocchi, C., \& Sivori, G. (2012). Food as trigger and aggravating factor of migraine. Neurological Sciences, 33(Suppl. 1), 77-80.

Food Regulations (1999). Government Notice No. 173 of 1999. The Food Act 1998: Regulations made by the Minister under Section 18 of the Food Act 1998. Available at:

http://health.govmu.org/English/Documents/reg-food.pdf [Accessed 18 January 2018].

Franzese, C. B. (2017). Advances in food allergy. Otolaryngologic Clinics of North America, 506), 1167-1173.

Fraser, O., Sumar, S., \& Sumar, N. (2000). Adverse reaction to foods. Nutrition and Food Science, $30(5), 236-242$.

Gray, C. L., Levin, M. E., Zar, H. J., Potter, P. C., Khumalo, N. P., Volkwyn, L., Fenemore, B., \& du Toit, G. (2014). Food allergy in South African children with atopic dermatitis. Pediatric Allergy and Immunology, 25(6), pp. 572-579.

Greiwe, J. C., Pazheri, F., \& Schroer, B. (2015). Nannies knowledge, attitude and management of food allergies in children: an online survey. Journal of Allergy and Clinical Immunology: In Practice, 3(1), 63-67.

Gupta, R. S., Springston, E. E., Warrier, M. R., Smith, B., Kumar, R., Pongracic, J. et al. (2011). The prevalence, severity, and distribution of childhood food allergy in the United States. Pediatrics, 128, e9-17.

Harrison, C., Jorder, M., Stern, H., Stavinsky, F., Reddy, V., Hanson, H., Waechter, H. Lowe, L., Gravano, L., \& Balter, S. (2014). Using online reviews by restaurant patrons to identify unreported cases of foodborne illness - New York City. Morbidity and Mortality Weekly Reports, 63(20), 441-445.

Hegde, V. L., Das, J. R., \& Venkatesh, Y. P. (2002). Anaphylaxis caused by the ingestion of cultivated mushroom (Agaricus bisporus): Identification of allergen as mannitol. Allergology International, 51(2), 121-129.

Helgesen, $\varnothing ., \&$ Nesset, E. (2010). Gender, store satisfaction and antecedents: a case study of a grocery store. Journal of Consumer Marketing, 27(2), 114-126. 
Joshi, P., Mofidi, S., \& Sicherer, S. H. (2002). Interpretation of commercial food ingredient labels by parents of food-allergic children. Journal of Allergy and Clinical Immunology, 109(6), 1019-1021.

Justin-Temu, M., Risha, P., Abla, O., \& Massawe, A. (2008). Incidence, knowledge and health seeking behaviour for perceived allergies at household level: a case study in Ilala district Dar es Salaam Tanzania, East African Journal of Public Health, 5, 90-93.

Juwaheer, T. D., Pudaruth, S., \& Ramdin, P. (2013). Enhancing customer shopping experience in malls of emerging countries - the "Mauritius" experience. World Journal of Entrepreneurship, Management and Sustainable Development, 9(2/3), 178-190.

Kemp, S. F., Lockey, R. F., Simons, F. E. R., \& the World Allergy Organization ad hoc Committee on Epinephrine in Anaphylaxis. (2008). Epinephrine: The drug of choice for anaphylaxis: A statement of the World Allergy Organization. World Allergy Organization, 1(Suppl. 2), pp. S18.

Kerbach, S., Alldrick, A. J., Crevel, R. W. R., Domotor, L., DunnGalvin, A., Mills, E. N. C., Pfaff, S., Poms, R. W., Popping, B., \& Tomoskozi, S. (2009). Managing food allergens in the food supply chain - viewed from different stakeholder perspectives. Quality Assurance and Safety of Crops \& Foods, $1(1), 50-60$.

Koyratty, B. N. S., Aumjaud, B., \& Neeliah, S. A. (2014). Food additive control: a survey among selected consumers and manufacturers. British Food Journal, 116(2), 353-372.

Kumar, S., Verma, A. K., Misra, A., Tripathi, A., Chaudhari, B., Prasad, R., Jain, S. K., Das, M., \& Dwivedi, P. D. (2011). Allergenic responses of red kidney bean (Phaseolus vulgaris CV Chitra) polypeptides in BALB/c mice recognized by bronchial asthma and allergic rhinitis patients. Food Research International, 44(9), 2868-2879.

Kung, S.-J., Steenhoff, A. P., \& Gray, C. (2014). Food allergy in Africa: Myth or reality? Clinical Reviews in Allergy \& Immunology, 46(3), 241-249.

Ladkin, A., \& Juwaheer, T. D. (2000). The career paths of hotel general managers in Mauritius. International Journal of Contemporary Hospitality Management, 12(2), 119-125.

Liu, A., \& Niyongira, R. (2017). Chinese consumers food purchasing behaviors and awareness of food safety. Food Control, 79, 185-191.

Lopata, A. L., O'Hehir, R. E., \& Lehrer, S. B. (2010). Shellfish allergy. Clinical \& Experimental Allergy, $40(6), 850-858$.

Lunet, N., Falcao, H., Sousa, M., Bay, N. \& Barros, H. (2005). Self-reported food and drug allergy in Maputo, Mozambique. Public Health, 119, 587-589.

Mfueni, E., Gama, A. P., Kabambe, P., Chimbaza, M., Matita, G., \& Matumba, L. (2018). Food allergen labelling in developing countries: Insights based on current allergen labelling practices in Malawi. Food Control, 84, 263-267.

Ministry of Health and Quality of Life (n.d.). Food Act 1998, Republic of Mauritius. Available at: http://health.govmu.org/English/Legislations/Pages/Foodact1998.aspx [Accessed 10 February 2018].

Naidoo, P., \& Ramseook-Munhurrun, P. (2016). Enclave resorts in Mauritius. In, P. L. Pearce, M.-Y. Wu (Eds.). The World Meets Asian Tourists (Bridging Tourism Theory and Practice), Vol. 7, Emerald Group Publishing, pp. 127-147. 
Nwaru, B. I., Hickstein, L., Panesar, S. S., Roberts, G., Muraro, A., Sheikh, A. et al. (2014).

Prevalence of common food allergies in Europe: a systematic review and meta-analysis. Allergy, 69, 992-1007.

Obeng, B. B., Amoah, A. S., Larbi, I. A., Yazdanbakhsh, M., van Ree, R., Boakye, D. A., \& Hartgers, F. C. (2011). Food allergy in Ghanaian schoolchildren: Data on sensitization and reported food allergy. International Archives Allergy Immunology, 155, 63-73.

Pascual, C. Y., Reche, M., Fiandor, A., Valbuena, T., Cuevas, T., \& Esteban, M. M. (2008). Fish allergy in childhood. Pediatric Allergy and Immunology, 19(7), 573-579.

Potter, P. C., Warner, J. O., Pawankar, R., Kaliner, M. A., Del Giacco, S., Rosewasser, L., \& WAO Specialty and Training Council (2009). Recommendations for competency in allergy training for undergraduates qualifying as medical practitioners: a position paper of the World Allergy Organization. World Allergy Organization, 2(8), 150-154.

Prescott, S. L., Pawankar, R., Allen, K. J., Campbell, D. E., Sinn, J. K. H., Fiocchi, A., Ebisawa, M., Sampson, H. A., Beyer, K., \& Lee, B.-W. (2013). A global survey of changing patterns of food allergy burden in children. World Allergy Organization, 6, 21.

Pugo-Gunsam, P., Cahoolessur, N., \& Subratty, A. H. (2008). A survey on reported symptoms of food hypersensitivity in Mauritius. Nutrition \& Food Science, 38(5), pp. 446-450.

Ramnauth, M., Driver, F., \& Vial, P. B. (2008). Food safety management in the fish industry in Mauritius: knowledge, attitude and perception. British Food Journal, 110(10), 989-1005.

Ramnauth, M., Vial, P. B., \& Driver, B. M. F. (2008). Characterisation of the fish producing and fish processing sectors in Mauritius. University of Mauritius Research Journal, 14(1), 37-48.

Salaun, Y., \& Flores, K. (2001). Information quality: meeting the needs of the consumer. International Journal of Information Management, 21, 21-37.

Sarinho, S., \& Lins, M. d. G. M. (2017). Severe forms of food allergy. Jornal de Pediatria, 93(Suppl. 1), 53-59.

Sharp, M., F., \& Lopata, A. L. (2014). Fish allergy: In review. Clinical Reviews in Allergy \& Immunology, 46(3), 258-271.

Sicherer, S. H., \& Sampson, H. A. (2018). Food allergy: A review and update on epidemiology, pathogenesis, diagnosis, prevention and management. Journal of Allergy and Clinical Immunology, 141(1), 41-58.

Simons, E., Weiss, C. C., Furlong, T. J., \& Sicherer, S. H. (2005). Impact of ingredient labelling practices on food allergic consumers. Annals of Allergy, Asthma and Immunology, 95(5), 426-428.

Singla, M. (2010). Usage and understanding of food and nutritional labels among Indian consumers. British Food Journal, 112(1), 83-92.

Soon, J. M., Singh, H., \& Baines, R. (2011). Foodborne diseases in Malaysia: A review. Food Control, 22(6), 823-830.

Soon, J. M. (In press). 'No nuts please': Food allergen management in takeaways. Food Control. DOI: doi.org/10.1016/j.foodcont.2018.04.024

Statistics Mauritius (2017). International travel and tourism. Available at: http://statsmauritius.govmu.org/English/Publications/Pages/Tourism_Jan-Sep17.aspx [Accessed 3 March 2018]. 
Subratty, A. H., Beeharry, P., \& Chan Sun, M. (2006). A survey of hygiene practices among food vendors in rural areas in Mauritius. Nutrition \& Food Science, 34(5), 203-205.

Verbeke, W., \& Ward, R. W. (2006). Consumer interest in information cues denoting quality, traceability and origin: An application of ordered probit models to beef labels. Food Quality and Preference, 176), 453-467.

Voordouw, J., Cornelisse-Vermaat, J. R., Yiakoumaki, V., Theodoridis, G., Chryssochoidis, G., \& Frewer, L. J. (2009). Food allergic consumers' preferences for labelling practices: a qualitative study in a real shopping environment. International Journal of Consumer Studies, 33(1), 94-102. Investigation on the understanding and implementation of food allergen management among Thai

Westritschnig, K., Sibanda, E., Thomas, W., Auer, H., Aspock, H., Pittner, G., Vrtala, S., Spitzauer, S., Kraft, D., \& Valenta, R. (2003). Analysis of the sensitization profile towards allergens in central Africa. Clinical \& Experimental Allergy, 33(1), pp. 22-27. 